\title{
STURGE WEBER SYNDROME: A CASE REPORT WITH CLINICAL AND RADIOLOGICAL FEATURES
}

Puneet Yadav로 Shifa Yadav², Jai Chowdhary³, Pawan Jain4, Hemant Kumar Mishra ${ }^{5}$

\section{HOW TO CITE THIS ARTICLE:}

Puneet Yadav, Shifa Yadav, Jai Chowdhary, Pawan Jain, Hemant Kumar Mishra. "Sturge Weber Syndrome: A Case Report with Clinical and Radiological Features". Journal of Evolution of Medical and Dental Sciences 2014; Vol. 3, Issue 46, September 22; Page: 11305-11309, DOI: 10.14260/jemds/2014/3476

\begin{abstract}
Sturge-Weber syndrome, sometimes referred to as encephalotrigeminal angiomatosis, is a rare congenital neurological and skin disorder. It is one of the phakomatoses and is often associated with port-wine stains of the face, glaucoma, seizures, mental retardation, and ipsilateral leptomeningeal angioma (cerebral malformations and tumors). It is characterized by abnormal blood vessels on the brain surface. Normally, only one side of the brain is affected. We report a case of 13 year old female child with facial port wine stains along with radiological features which showed tram track sign and cortical atrophy in the right parietal lobe.
\end{abstract}

KEYWORDS: Port wine stain, Sturge-Weber syndrome, clinical, Radiological findings.

INTRODUCTION: Sturge-Weber syndrome (SWS) belongs to a group of disorders collectively known as the phakomatoses ("mother-spot" diseases). It consists of congenital hamartomatous malformations that may affect the eye, skin, and central nervous system (CNS) at different times, characterized by the combination of venous angiomas of leptomeninges, face, jaws and oral soft tissues. [1] SWS was first described by Schirmer in1860. More specific description was given by Sturge in 1879. [2] SWS is believed to be caused by the persistence of vascular plexus around the cephalic portion of the neural tube. This plexus develops during the sixth week of intra uterine development but normally undergoes regression during ninth week. [3]

Angiomas of leptomeninges are usually unilateral, located in parietal and occipital region. The presence of angioma results in alteration of vascular dynamics causing precipitation of calcium deposits in cerebral cortex underlying the angioma. Seizures, mental retardation, hemiplegia, or hemiparesis may develop secondary to this and their severity depends on the extent of lesion. [4]

The cutaneous angiomas are called port wine stains, which usually occur unilaterally along dermatomes supplied by the ophthalmic and maxillary division of trigeminal nerve. It may be bilateral or totally absent or may extend to neck, limbs and other parts of the body.[4] Involvement of the area supplied by ophthalmic division is pathognomic.

Ocular involvement can result in glaucoma, choroidal hemangioma, bupthalmos, or hemianopis. ${ }^{[5]}$ Intraoral angiomatosis may involve lips, buccal mucosa, palate, gingiva, and floor of mouth. This syndrome is of rare occurrence and management becomes complicated due to risk of hemorrhage.

CASE REPORT: A 13-year-old female patient reported to the department of radio-diagnosis from skin OPD for MRI Brain with chief complaints of reddish discoloration on forehead, seizures and low intelligence. History revealed that the reddish discoloration (port wine stain) was present on her face since birth and was gradually darkening with age. She was youngest of the three siblings born at full term by normal delivery. Family history was noncontributory. Patient was illiterate. 
There was visible sign of mental retardation and patient had history of convulsions. Examination revealed that the port wine stain involving middle of forehead. [Fig.1] On radiological examination, X-ray showed the tram-track type calcification in the parietal lobe. [Fig. 2] CT scan revealed atrophy involving right cerebral hemisphere with prominent sub-arachnoid spaces, predominantly involving the fronto-parietal lobes with evidence of tram-track or gyriform calcification pattern seen in right parietal lobe. [Fig. 3a, b, c]

MRI scan revealed atrophy involving right cerebral hemisphere with prominent right choroid plexus and sub-arachnoid spaces, predominantly involving the fronto-parietal lobes with evidence of tram-track or gyriform calcification pattern seen in right parietal lobe. [Fig. 4a, b, c] With the help of clinical and radiological findings a diagnosis of sturge weber syndrome was made.

Fig. 1: Port wine stains on forehead.

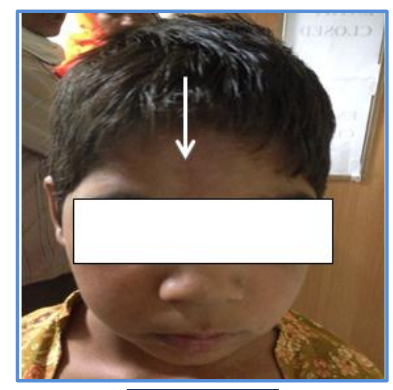

\section{Fig. 1}

Fig. 2: X-ray skull lateral view showing tram-track/gyriform pattern calcification in parietal lobe.

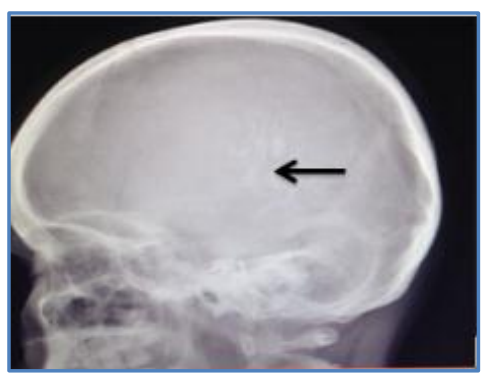

Fig. 2

Fig. 3a: NCCT axial image showing cortical atrophy and tram-track pattern calcification in right parietal lobe.

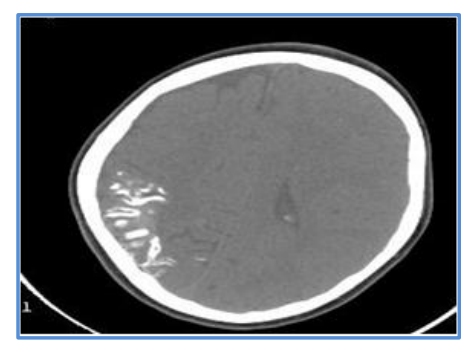

Fig. 3a 


\section{CASE REPORT}

Fig. 3b, 3c: NCCT sagittal image showing prominent sub-arachnoid spaces and tram-track pattern calcification.

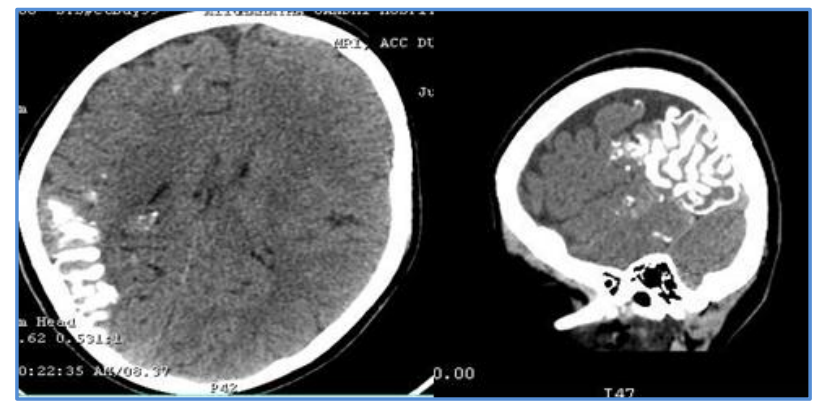

Fig. 3b, 3c

Fig. 4a, b, c, d: MRI FLAIR, T2W and T1W axial images showing atrophy of right cerebral hemisphere with prominent sub-arachnoid spaces involving fronto-parietal lobes with prominent right choroid plexus on right side.
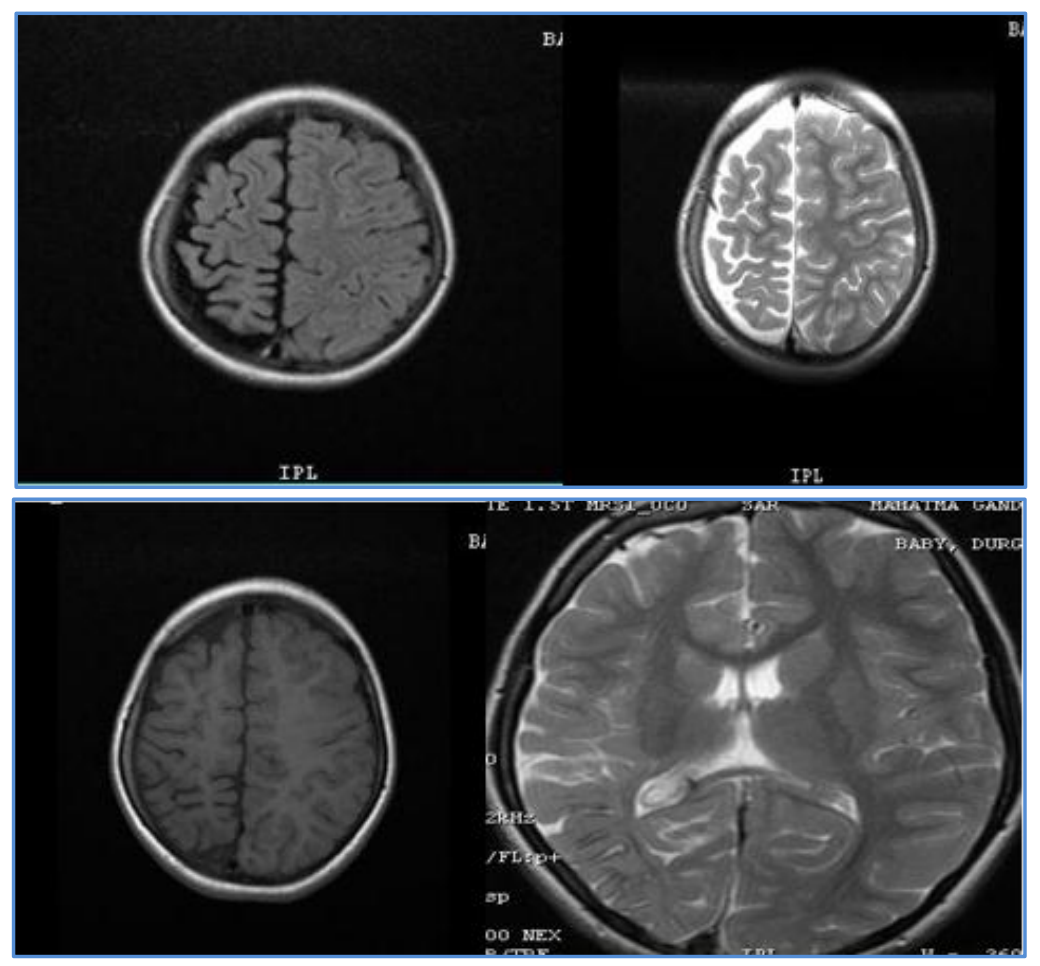

Fig. $4 a, 4 b, 4 c, 4 d$

DISCUSSION: Port wine stains represent hamartomatous capillary malformations and are named so due to the deep red hue that they leave on the skin or mucosa. ${ }^{6]}$ Such lesions characteristically bleed profusely when traumatized. In our case, the patient had port wine stain on her forehead. Not all patients with facial port wine stains have Sturge - Weber angiomatosis.

Only patients with involvement along the distribution of the ophthalmic branch of trigeminal nerve are at risk for the development of full condition. [3] 
SWS is referred to as complete when both CNS and facial angiomas are present and incomplete when only one area is affected without the other. The Roach scale [7] is used for classification:

Type I: Both facial and leptomeningeal angiomas; may have glaucoma.

Type II: Facial angiomas alone; may have glaucoma.

Type III: Isolated leptomeningeal angiomas; usually no glaucoma.

Our patient had only facial angioma which comes under Type II of SWS according to Roach scale. Differential diagnosis includes (1) Rendu-Oslar-Weber syndrome-Hereditary condition characterized by abnormal dilatation of terminal vessels of skin, mucosa and occasionally viscera. Epistaxis is most common. (2) Angio-osteodystrophy syndrome- characterized by port wine stains on face, varices and hypertrophy of bones. (usually long bones) (3) Maffuci's syndrome-characterized by multiple angiomas of skin and chondromas of bone. (4) Von Hippel Lindau disease- a familial syndrome involving hemangioblastoma in retina and cerebellum. (5) Klippel Trenaumy-Weber syndrome- is a syndrome characterized by combination of capillary malformation, soft tissues, bone hypertrophy and venous malformations. [4, 8]

The diagnosis is based on clinical and imaging studies. Port wine nevus is observed clinically. Skull films may reveal tram track calcification caused by calcification in apposing gyri, ipsilateral calvarial thickening and enlargement of the paranasal sinuses and mastoid. Cranial CT scan revealing cortical atrophy underlying the angioma with gyriform 'tram-track' calcifications is the characteristic imaging feature. In our patient, Cranial CT showed cortical atrophy with tram track calcification. MRI is the current gold standard for diagnosis of the disease which is reliable even in very young infants. (10) MRI of our patient showed atrophy of right cerebral hemisphere and prominent subarachnoid spaces in fronto-parietal lobes with prominent right choroid plexus.

New born babies with a port wine stains should have an ophthalmological examination in the first month of life, followed by neuroimaging (CT and gadolinium enhanced MRI) by 6-12 months age or sooner if neurologic signs are present. Cerebral blood flow imaging, Single Photon Emission Computed Tomography (SPECT) and Positron Emission Tomography (PET) are also useful when possible. The neurological signs are due to ipsilateral leptomeningeal angioma involving the occipital and posterior parietal lobes of the brain; vascular stasis with resultant ischemia leads to calcification and laminar cortical necrosis.

Management of the syndrome involves both medical and surgical approaches. Medical treatment includes anticonvulsant therapy with prophylactic low dose aspirin to prevent thrombus formation. At present, there is no evidence base to suggest one particular anti-epileptic drug above another, thus use of local clinical guidelines is recommended. Acute rescue treatment of seizures with benzodiazepines or if ineffective, intravenous phenytoin or phenobarbitone is recommended in India.(11)

PWS may be treated with cosmetic camouflage creams, pulsed tunable dye laser and cosmetic surgery. Laser therapy is the most effective approach to therapy of the PWS, but results are extremely variable being considered satisfactory in only $45 \%$ cases. The development of a multicentre network for SWS trials has been proposed due to current controversies in management of the seizures, other neurologic impairment and the skin lesions. Early surgery is advocated for better seizure control and to prevent developmental delay. (12) 


\section{REFERENCES:}

1. Rajendran R. Benign and malignant tumors of oral cavity. In: Rajendran R, Sivapatha Sundharam B, editors. Shafer's Textbook of Oral Pathology. 6th ed. Noida: Elsevier; 2009. pp. 144-5.

2. Caiazzo A, Mehra P, Papagearge MB. The use of preoperative percutaneous transcatheter vascular occlusive therapy in the management of Sturge -Weber syndrome - Report of a case. J Oral Maxillofac Surg. 1998; 56: 775-8.

3. Neville BW, Damm DD, Allen CM, Bouquot JE, editors. 3rd ed. St. Louis: Elsevier; 2009. Oral and Maxillofacial Pathology.

4. Suprabha B, Baliga S. Total oral rehabilitation in a patient with port wine stains. J Indian Soc Pedod Prev Dent. 2005; 23: 99-102.

5. Gorlin RJ, Pindborg JJ. New York: McGraw- Hill; 1964. Syndromes of head and neck; pp. 406-9.

6. Fishman SJ, Muliken JB. Hemangiomas and vascular malformations of infancy and childhood. Pediatr Clin North Am. 1993; 40: 1177-200.

7. Roach ES. Neurocutaneous syndromes. Pediatr Clin North Am. 1992; 39: 591-620.

8. Mukhopadhyay S. Sturge -Weber syndrome: A Case report. J Indian Soc Pedod Prev Dent. 2008; 26: 29-31.

9. Yukna RA, Cassingham RJ, Carr RF. Periodontal manifestations and treatment in a case of Sturge -Weber syndrome. Oral Surg Oral Med Oral Pathol. 1979; 47: 408-15.

10. Comi AM. Sturge-Weber syndrome and epilepsy: an argument for aggressive seizure management in these patients. Expert Rev Neurother2007; 7: 951-956.

11. Rochkind S, Hoffman HJ, Hendrick EB. Sturge-Weber syndrome: natural history and prognosis. J Epilep1990; 3: 293.

12. Sarah A. Sturge Weber syndrome: A Review. Ann Indian Acad Neurol 2007; 10: 55-58.

\section{AUTHORS:}

1. Puneet Yadav

2. Shifa Yadav

3. Jai Chowdhary

4. Pawan Jain

5. Hemant Kumar Mishra

\section{PARTICULARS OF CONTRIBUTORS:}

1. $3^{\text {rd }}$ year Resident, Department of Radiodiagnosis, Mahatma Gandhi Hospital, Sitapura, Rajasthan.

2. $2^{\text {nd }}$ year Resident, Department of Radiodiagnosis, Mahatma Gandhi Hospital, Sitapura, Rajasthan.

3. Senior Resident, Department of Radiodiagnosis, Mahatma Gandhi Hospital, Sitapura, Rajasthan.

4. Associate Professor, Department of Radiodiagnosis, Mahatma Gandhi Hospital, Sitapura, Rajasthan.
5. Professor, Department of Radiodiagnosis, Mahatma Gandhi Hospital, Sitapura, Rajasthan.

\section{NAME ADDRESS EMAIL ID OF THE CORRESPONDING AUTHOR:}

Dr. Puneet Yadav, Room No. 11, PG Hostel, Type-IV A, Mahatma Gandhi Hospital, Jaipur.

Email: puneetrao07@gmail.com

Date of Submission: 30/08/2014. Date of Peer Review: 31/08/2014. Date of Acceptance: 12/09/2014. Date of Publishing: 22/09/2014. 